\title{
Associations between the school climate and student life satisfaction: Resilience and bullying as mediating factors
}

\author{
Jill M. Aldridge, Katrina McChesney, and Ernest Afari
}

This is the authors' accepted manuscript.
The Version of Record of this manuscript was published on 7 September 2019 and is
available in Learning Environments Research (advance online publication)
https://link.springer.com/article/10.1007/s10984-019-09296-9

\begin{abstract}
Adolescent life satisfaction is associated with important affective, behavioural, and health-related outcomes during both adolescence and later life; therefore, strategies for promoting adolescent life satisfaction have potential social value. The study reported in this article examined associations between perceptions of the school climate and reports of bullying, resilience, and life satisfaction for 6,120 Australian adolescents. The study extended past research, which has given little attention to either the relationships between these variables or the relative roles of various school climate sub-constructs. Aspects of the school climate explained $41 \%$ of the variance in adolescents' resilience, $16 \%$ of the variance in bully victimisation, and 54\% of the variance in life satisfaction. Further, resilience was positively associated with life satisfaction. These results affirm the importance of the psychosocial school climate as a mechanism for improving adolescent (and life-course) outcomes, strengthening calls for schools to give greater attention to improving their psychosocial climates.
\end{abstract}

\section{Keywords}

School climate, life satisfaction, resilience, bullying, wellbeing, student perceptions 


\section{ORCID details}

Jill Aldridge: 0000-0003-0742-0473

Katrina McChesney: 0000-0002-3991-6265

Ernest Afari: 0000-0003-2814-4439

\section{Contact details}

Jill M. Aldridge (corresponding author)

School of Education

Curtin University

GPO Box U1987

Perth WA 6845

Australia

j.aldridge@curtin.edu.au

+61892663592

\section{Acknowledgements}

The research reported in this article was supported by the Australian Research Council (grant number LP110200285). 


\title{
Associations between the school climate and student life satisfaction: Resilience and bullying as mediating factors
}

\author{
Jill M. Aldridge, Katrina McChesney, and Ernest Afari
}

\begin{abstract}
The gross national product does not allow for the health of our children, the quality of their education or the joy of their play. It does not include the beauty of our poetry or the strength of our marriages, the intelligence of our public debate or the integrity of our public officials. It measures neither our wit nor our courage, neither our wisdom nor our learning, neither our compassion nor our devotion to our country; it measures everything in short, except that which makes life worthwhile.
\end{abstract}

- Robert F. Kennedy, Remarks at the University of Kansas, March 18, 1968

Although education - and, indeed, life — is often conceptualised in terms of performative, economic, or outcomes-based measures, Robert Kennedy's words reflect the increasingly-acknowledged view that such measures miss much of the human experience. For both youth and adults, affective or subjective forms of well-being are important determinants of present and future functioning (Proctor et al. 2009; Suldo et al. 2009). Research methods have been developed to allow these constructs to be meaningfully assessed (Diener et al. 2013; Huebner and Gilman, 2014), and, in the past decade, numerous initiatives have been launched to monitor wellbeing at scale, reflecting global awareness of the importance of such constructs (see, for example, ACSPRI n.d.; OECD n.d.; UK Office for National Statistics n.d.; United Nations n.d.). This awareness has also resulted in increased research attention being given to positive psychology in educational settings (Mok 2018; Seligman et al. 2009).

Although life satisfaction at all stages of life is desirable, adolescent life satisfaction, in particular, is associated with a number of important affective, behavioural, and health-related outcomes during both adolescence and later life (Antaramian et al. 2008; Currie et al. 2012; 
Hills et al. 2014; Proctor et al. 2009; Suldo et al. 2009). As such, efforts to promote adolescent life satisfaction may constitute effective social investments through reducing inequity and improving outcomes over the life course.

Most children and adolescents report high life satisfaction (Australian Psychological Society 2016; Currie et al. 2012; UK Office for National Statistics 2016); however, a significant minority do not. For example, a 2016 study in Australia (where the present research took place) found that $15 \%$ of Australian adolescents were unsatisfied with their lives (Australian Psychological Society 2016). Life satisfaction has been found to decline significantly between the ages of 11 and 15 (Currie et al. 2012), and some demographic inequities have been observed (Proctor et al. 2009). As such, there is scope for improvement and deliberate intervention in the area of adolescent life satisfaction.

\section{Present Study}

This article reports on an investigation of the relationships between adolescent life satisfaction, resilience, experiences of bullying, and school climate. Although a range of factors (discussed in the next section) are known to influence life satisfaction, these factors vary in terms of their amenability to change (Hills et al. 2014; Suldo et al. 2009). Given that past literature suggests that schools may be able to influence school climate, student resilience, and experiences of bullying, the aim of this study was to use student self-report data to test a hypothesised conceptual model of the relationships between these variables and students' life satisfaction. Our conceptual model is presented later, following a review of relevant literature.

Limited prior research has examined how either bully victimisation or resilience are associated with adolescent life satisfaction, and no studies (to our knowledge) have investigated school climate, bully victimisation, resilience, and life satisfaction in combination. Further, although there is general support for the view that school climate influences adolescent life satisfaction, the specific aspects of school climate that exert this influence are less wellunderstood (Suldo et al. 2008; Suldo et al. 2009). Our study, therefore, extends the existing 
literature and has the potential to support educators in identifying effective strategies and priorities for maximising adolescent life satisfaction and the associated outcomes.

\section{Literature Review}

\section{School Climate}

For this study, school climate was defined as the attitudes, norms, beliefs, values, and expectations that underpin school life and affect the extent to which members of the school community feel safe (Aldridge et al. 2016; Aldridge et al. 2017; Cohen et al. 2009). Our focus was on the psychosocial, school-level climate (and not, for example, the physical environment or the classroom-level climate).

The importance of the psychosocial school climate is well-documented. School climate is associated with a range of academic, social, psychological, and health-related outcomes for students both during schooling and over the life course (Aldridge and McChesney 2018; Cohen et al. 2009; Felner et al. 2001). Although climate affects all students, equity issues arise as negative school climates are disproportionately influential on students from racial or ethnic minorities (Center for School Health and Education 2011) or low-income families (Hopson and Lee 2011; see also Felner et al. 2001). Many schools' climates are far from ideal, partly due to a lack of teacher awareness of the importance of school climate; Cohen et al. (2009, p. 181) have described this situation as 'socially unjust and a violation of children's human rights' (see also Felner et al. 2001).

School climate was operationalised for the present study using six constructs. These were defined as follows (Aldridge and Ala'i 2013; Aldridge et al. 2017; Riekie et al. 2017):

- Teacher support examined the quality of student-teacher relationships and students' perceptions that their teachers valued and supported them;

- Peer connectedness examined the quality of inter-student relationships, including relationships across different groups of students; 
- School connectedness examined the degree to which students felt a sense of attachment, belonging and connectedness to the school;

- Affirming diversity examined the degree of acknowledgement, acceptance, inclusion, and valuing shown to students of differing backgrounds and experiences;

- Rule clarity examined the extent to which students felt the school rules were clear and appropriate; and

- Reporting and seeking help examined students' awareness of school procedures for reporting issues and their willingness to make use of these.

These dimensions of school climate are supported within the literature. For example, a recent review by Berkowitz et al. (2017) noted that teacher support, school connectedness, and school safety (reflected in our constructs of rule clarity and reporting and seeking help) are 'central components that recur in the majority of definitions and measurements' of school climate (p. 7). The same review also recommended that future studies investigate relational trust and respect for diversity; these correspond to our peer connectedness and affirming diversity constructs.

\section{Resilience}

Resilience is a strengths-based concept that refers to an individual's ability to thrive, succeed or bounce back in the face of stress, obstacles or adversity (Benard 1997; Cohen 2013). Resilient children demonstrate social competence, problem-solving skills, autonomy, and a sense of purpose and future (Benard 1997, 2004). The emergence of resilience is a normal developmental response to life events (Masten 2001), and resilience is influenced by a range of factors including experiences of stress, obstacles, or adversity; coping strategies; circumstances; and the availability of supportive social capital (Masten et al. 2008; O’Dougherty Wright et al. 2013; Rutter 2006). However, resilience can also be deliberately learned and developed (Benard and Slade 2009; Cohen 2013, Seligman et al. 2009), supporting its potential role as a lever with 
which schools can influence other outcomes (such as life satisfaction) that are more difficult to influence directly.

Resilience has been found to be a protective factor against a range of negative outcomes. All youth will encounter risks and adversities at some point, but resilience reduces youths' vulnerability in those encounters (Friedli 2009; Goldstein and Brooks 2005). As such, resilience minimises the 'negative chain effect' (Schoon and Bynner 2003, p. 23) that is otherwise associated with the accumulation of risk factors and adverse experiences (see also Fergusson and Horwood 2003).

Schools are an important site for efforts to promote resilience among adolescents. Key protective and promotive factors for resilience that are relevant in school contexts include positive relationships with caring adults, problem-solving skills, perceived efficacy and autonomy, motivation to achieve, persistence, self-regulation, positive peer relationships, and effective teaching (Masten et al. 2008). Further, school climate is non-neutral in relation to students' resilience: Whereas positive school climates promote resilience, negative school climates can constitute a further risk factor jeopardising students' resilience (Masten et al. 2008; Reyes et al. 2013). These effects are magnified disproportionately for those students who may be most at risk, given their accumulation of other risk factors and adverse experiences and the lack of protective factors in their home or community contexts (Hopson and Lee 2011; Masten et al. 2008; Reyes et al. 2013). Finally, the amount of time adolescents spend in school makes schools ideal contexts for the widely advocated primary prevention approach, which aims at developing resilience in all students rather than focusing only on crisis intervention (Benard and Slade 2009; Currie et al. 2012; Reyes et al. 2013; Schoon and Bynner 2003; Seligman et al. 2013).

\section{Bullying}

For the purpose of this study, bullying was defined as intentional, repeated, negative behaviour on the part of one or more students, toward one or more other students, in the context 
of a real or perceived power imbalance (National Center for Injury Prevention and Control 2014; Olweus 1994). This definition encompasses physical aggression, verbal abuse, relational behaviours (such as rumour-spreading or social exclusion) and cyber-bullying. Our interest, for this study, specifically related to the experiences of those who are victims (rather than perpetrators or bystanders) of bullying.

Bullying remains prevalent among adolescents, although estimates of the prevalence rates vary greatly, partly due to differing definitions or operationalisations of bullying (Hong and Espelage 2012; Modecki et al. 2014). Experiences of bullying are associated with negative outcomes including substance abuse (Hoffman et al. 2016; Mitchell et al. 2007; Turner 2013); involvement in violence and crime (Aldridge et al. 2017; Hoffman et al. 2016; Mitchell et al. 2007; National Center for Injury Prevention and Control 2014; Turner 2013); and reduced mental health and subjective wellbeing (Mitchell et al. 2007; National Center for Injury Prevention and Control 2014).

Given that most youth bullying occurs within schools (Kasen et al. 2004), much research has examined the relationship between school climate and bullying. Overall, school climate is negatively associated with the prevalence of bullying (Wang et al. 2013). Specific aspects of school climate that have been found to reduce bullying rates include: supportive peer relationships (Demaray and Malecki 2003; Li et al. 2011; Turner et al. 2014); supportive relationships with teachers (Demaray and Malecki 2003; Li et al. 2011; Olweus 1994); school connectedness and engagement ( $\mathrm{Li}$ et al. 2011; Turner et al. 2014); clear boundaries and consequences for unacceptable behaviour (Olweus 1994); and school-wide normative beliefs regarding bullying (Gendron et al. 2011). Further, the school climate may influence students' resilience and response to bullying (Eliot et al. 2010). Together, these findings point to the importance of modifying school climate as a means of preventing or minimising bullying (Wang et al. 2013). 


\section{Life Satisfaction}

Life satisfaction relates to a person's cognitive satisfaction or contentment with their quality of life (Aldridge et al., 2016; Hills et al. 2014; Suldo et al. 2008). Life satisfaction can be examined both globally (across all areas of a person's life) and for specific domains (for example, satisfaction with one's relationships or employment; see Huebner and Gilman 2014; Suldo et al. 2008). Global, rather than domain-specific, life satisfaction was examined in this study.

A range of factors have been shown to contribute to adolescent life satisfaction (Huebner et al. 2004; Huebner et al. 2012; Proctor et al. 2009). Of these, personality traits, dispositions, and cognitive attributes (such as self-esteem or internal locus of control) are, to a large extent, innate. Many environmental factors and life experiences that affect adolescent life satisfaction (such as family conflicts, parenting styles, parental divorce, accidental injury, or loss of loved ones) are, likewise, difficult to influence (Hills et al. 2014). On the other hand, some environmental influences can be more easily modified, and adolescent life satisfaction has been shown to be sensitive to such interventions (Huebner et al. 2012).

One such environmental factor that may be 'amenable to change' (Suldo et al. 2009, p. 31) for the purpose of promoting adolescent life satisfaction is school climate. Existing research suggests that adolescents' global life satisfaction may be influenced by several aspects of school climate, including: peer relationships (Suldo et al. 2013); student-teacher relationships and support (Suldo et al. 2008; Suldo et al. 2013); school connectedness or attachment (Suldo et al. 2008; You et al. 2008); and schoolwide order and discipline (Suldo et al. 2013).

Experiences of bully victimisation may also (negatively) affect adolescents' life satisfaction; these experiences may be prevented or minimised through deliberate interventions at the school level. However, only two studies were able to be located that had previously explored this possibility. In a longitudinal study, Martin et al. (2008) found evidence to suggest that there may be bidirectional relationships between bully victimisation and life satisfaction and called for future research to further clarify this interaction. In a cross-sectional, multigroup 
analysis, You et al. (2008) found that the association between school connectedness and life satisfaction was statistically significant only for those students who had not been victims of bullying, suggesting that experiences of bully victimisation mediated the effect of school connectedness on life satisfaction.

Resilience, on the other hand, may protect students' life satisfaction, given that resilience reduces people's vulnerability to the negative outcomes that might otherwise result from adverse experiences (Goldstein and Brooks, 2005). Whereas some previous studies have suggested that life satisfaction is itself a resilience-like mediator against the negative outcomes associated with adverse experiences (McKnight et al. 2002; Suldo and Huebner, 2004), we chose to treat resilience and life satisfaction as distinct constructs, hypothesising that resilience would moderate the effects of negative experiences (specifically, a negative school climate) on life satisfaction.

\section{Contribution of the Present Study}

Overall, the existing literature suggests that there are important associations between school climate, resilience, bully victimisation, and life satisfaction for adolescents. However, our understanding of how these constructs interact in combination needs further refinement. For example, although the bivariate associations between positive school climates and resilience are well documented (Masten et al. 2008), it is not yet known whether resilience can moderate the impact of negative school climates on adolescent life satisfaction. Likewise, the potential role of bully victimisation in mediating the relationship between school climate and life satisfaction warrants further examination.

This study, therefore, progresses the field through our examination of the interrelationships between school climate, resilience, bully victimisation and life satisfaction. Further, our comprehensive operationalisation of school climate using six distinct subconstructs affords in-depth examination of the roles of particular aspects of the school climate, allowing for the identification of priority areas to guide school improvement efforts. 


\section{Research Methods}

\section{Conceptual Model}

A conceptual model (shown in Figure 1) was developed based on the review of research reported above. Our model incorporated six elements of school climate (defined in the next section); we hypothesised that some or all of these elements would be associated with life satisfaction both indirectly and directly:

Hypothesis 1. Students' perceptions of the school climate will be positively related to selfreports of resilience.

Hypothesis 2. Students' perceptions of the school climate will be negatively related to selfreports of bully victimisation.

Hypothesis 3. Students' perceptions of the school climate will be positively related to selfreports of life satisfaction.

Hypothesis 4. The relationship between students' perceptions of the school climate and their life satisfaction will be mediated by their sense of resilience and experiences of bullying victimisation.

Figure 1 about here

\section{Participants}

Participants for the present study were students from 17 co-educational high schools ( $n=8$ public and $n=9$ private) located in the metropolitan areas of Adelaide and Perth (the capitals of South Australia and Western Australia, respectively). Although this sample was not random, the schools varied in terms of enrolment size (ranging from 454 students to 1,353 students) and in terms of socio-economic status (based on the government-provided Index of Community Socio-Educational Advantage scores retrieved from www.myschool.edu.au).

At each school, all of the students who were present during data collection were invited to participate. The response rate was $76.2 \%$, providing a sample of 6,120 students from years 7 to 12 . When gender, birthplace, and first language statistics for this sample were compared to 
those for the Australian population (as reported in Table 1), the sample was considered to be generally representative of the population.

Table 1 about here

\section{Instruments and Measures}

This section describes the instruments and measures used in the study. Full details of the items in each instrument are available from the first author upon request.

School climate. A modified version of the What's Happening in this School? (WHITS) questionnaire was used to capture students' perceptions of the school climate. The WHITS, developed in Australia by Aldridge and Ala'i (2013), examines six aspects of school climate (teacher support, peer connectedness, school connectedness, affirming diversity, rule clarity, and reporting and seeking help) and has been reported to have satisfactory reliability and validity in two previous studies (Aldridge et al. 2016; Riekie et al. 2017). To provide a more economical version of the survey, we removed the two items from each scale that contributed the least information. Decisions about which items to remove were based on the factor loadings obtained in a previous study (Aldridge \& Ala'i 2013). The modified version involved 36 items (six items in each of the six original scales), which were responded to using a five-point frequency-response scale: almost never, rarely, sometimes, often, and almost always.

Resilience. To assess students' self-reports of resilience, we used a modified version of a scale that was originally developed by Wagnild and Young (1993). The modified measure used in our study was shown to have satisfactory psychometric properties in two previous studies (Aldridge et al. 2016; Riekie et al. 2017). This resilience scale examined underlying concepts such as perseverance, meaningfulness, and self-reliance and included items such as 'I come through difficult times with little trouble.' The items used the same five-point frequencyresponse format as for the WHITS. 
Bully victimisation. To examine students' self-reports of bully victimisation, a scale was modified from a survey developed by Bandyopadhyay et al. (2009). The version used in our study comprised six items that assessed the extent to which students felt that they had been victims of bullying behaviour (physical, emotional, or social). Students provided a retrospective self-report of bullying episodes that they had experienced over the past three weeks, with a fivepoint frequency-response format: never, once, twice, three times, and four or more times. The scale included items examining physical, verbal, and written forms of bullying (for example, 'I have experienced verbal bullying'); as such, the overall result was an index of bullying experience.

Life satisfaction. To measure life satisfaction, we used a modified version of the Satisfaction with Life scale (Diener et al. 2013). The modified scale, which was reported to have satisfactory reliability in two prior studies (Aldridge et al. 2016; Riekie et al. 2017), involved six items that provided an indication of students' satisfaction with their life over the past three weeks (such as 'I would change nothing about my life' and 'I have been satisfied with my life'). The life satisfaction scale used the same five-point frequency-response format as for the WHITS.

\section{Data Analysis}

This section summarises the steps involved in the data analysis for this study. Further information, including the specific criteria used for each statistical measure, is provided in Table 2. All analyses were conducted using AMOS version 22 software.

Table 2 about here

To examine the suitability of the data for structural equation modelling (SEM) analysis, the skewness and kurtosis of the data were examined. The skewness index ranged from -0.33 to -1.12 , which was acceptable, but the kurtosis index ranged from -30 to -1.42 , indicating that 
the individual items did not meet the requirement of univariate normality (Kline 2011). Given that the maximum likelihood-based chi-squared can be inflated with non-normal data (Curran et al.1996), AMOS 22's Bollen-Stine bootstrap (Bollen and Stine 1993) with a 1000-bootstrap sample was used to address issues of non-normality. The Mardia's coefficient was 484.35 , which, as recommended by Raykov and Marcoulides (2008), was less than $p(p+2)$, where $p$ is the total number of observed indicators (for our data, $p=54$ ). This result indicated that the data satisfied the requirement of multivariate normality and was, therefore, fit to be analysed using structural equation modelling (with the use of bootstrapping to account for the non-normal kurtosis).

Confirmatory factor analysis was then conducted to provide support for the reliability and validity of the proposed model. The item reliabilities and the composite reliability (CR) of each construct were examined; the CR is similar to Cronbach's alpha except that it takes into account the actual factor loadings rather than assuming that each item is equally weighted in the composite-load determination. We used the average variance extracted (AVE) for each construct to examine the convergent validity of the measurement model, and we used the square root of the AVE for each construct to examine the model's discriminant validity.

To test the research hypotheses, the fit of the proposed SEM model (based on the conceptual model shown in Figure 1) was examined. Given that the chi-square goodness of fit test is sensitive to sample size, the model fit was determined using the chi-squared/degrees of freedom ratio $\left(\chi^{2} / \mathrm{df}\right)$, Tucker-Lewis index (TLI), incremental fit index (IFI), comparative fit index (CFI), adjusted goodness of fit index (AGFI), root mean square error of approximations (RMSEA), and standardised root mean squared residual (SRMR). Table 2 specifies the criteria used for these statistical measures. The explanatory power of the proposed model was examined using the coefficient of determination $\left(R^{2}\right)$ for each outcome variable. Finally, to examine the magnitude and statistical significance of the relationships in the model, path coefficients and $p$ values were calculated. 


\section{Results and Discussion}

\section{Evaluation of the Structural Equation Model}

Confirmatory factor analysis was used to provide support for the reliability of the structural model in terms of convergent and discriminant validity. The full factor analysis results are available from the first author on request. The standardised factor loadings ranged from .61 to .91 , and, as shown in Table 3, the composite reliabilities ranged from .86 to .93 . These results demonstrated convergent validity at the item and construct levels. The AVE values (also shown in Table 3 ) ranged from .50 to .68 , demonstrating convergent validity at the model level. Further, for all constructs, the square root of the AVE (also reported in Table 3) met the criterion for divergent validity.

Table 3 about here

In terms of the model fit, the Bollen-Stine $p$-value for the overall model fit was .001, and the mean chi-squared value was 1717.37 (1325 degrees of freedom). Overall, the model fit was acceptable $\left(\chi^{2} / \mathrm{df}=1.30 ; \mathrm{TLI}=.96 ; \mathrm{IFI}=.96 ; \mathrm{CFI}=.96 ; \mathrm{GFI}=.93 ; \mathrm{AGFI}=.93 ; \mathrm{RMSEA}=.034\right.$; SRMR=.036).

In terms of the explanatory power of the research model, the coefficients of determination $\left(R^{2}\right)$ for the three outcome variables, reported in Table 4, indicated that the model explained acceptable proportions of the variance in the resilience, bully victimisation, and life satisfaction data.

Table 3 about here

Table 4 about here 
Having determined that the model fit was acceptable, the statistically significant relationships between the constructs in the model (using the bootstrap results) were examined. Of the 20 possible relationships, 13 were statistically significant $(p<.05)$, as shown in Figure 2. These findings are detailed and discussed below in relation to the four hypotheses that framed the study.

Figure 2 about here

\section{Hypothesis 1-Relationships between School Climate and Resilience}

The school climate explained $41 \%$ of the variance in student resilience. Four aspects of school climate were statistically significantly and positively related to students' sense of resilience: peer connectedness $(\beta=0.19, p<.001)$, school connectedness $(\beta=0.27, p<.001)$, rule clarity $(\beta=0.15, p<.001)$, and reporting and seeking help $(\beta=0.12, p<.001)$.

These findings suggest that the more positively that students perceive these aspects of the school climate, the more resilient the students report themselves to be. This supports past research, which has indicated that higher levels of resilience are associated with students' experiences of strong and positive peer relationships (Riekie et al. 2017); a sense of belonging and being valued by the school (Aldridge et al. 2016; Riekie et al. 2017); and schools that have clear rules and expectations (Benard 2004; Riekie et al. 2017).

\section{Hypothesis 2-Relationships between School Climate and Bully Victimisation}

The school climate explained $16 \%$ of the variance in bully victimisation. Students who perceived more teacher support $(\beta=-0.06, p<.01)$, school connectedness $(\beta=-0.42, p<.001)$, and rule clarity $(\beta=-0.05, p<.05)$ reported less bully victimisation; the stronger effect (indicated by the larger absolute beta value) for school connectedness is particularly noteworthy. On the other 
hand, students who reported more affirming diversity $(\beta=0.05, p<.05)$ and reporting and seeking help $(\beta=0.06, p<.01)$ reported slightly more bully victimisation.

The negative relationships between three of the school climate scales (teacher support, school connectedness, and rule clarity) and bully victimisation support existing literature, which has highlighted the relationships between such environmental factors and the prevalence of bullying (Demaray and Malecki 2003; Li et al. 2011; Olweus 1994; Turner et al. 2014; Wang et al. 2013). Our results suggest that schools may be able to reduce the prevalence of bullying by enhancing students' sense of belonging and support at school as well as the clarity of school rules and expectations. Given that a wide range of programmes have been developed to target bullying within schools, our findings might be incorporated to enhance the efficacy of such programmes.

On the other hand, the results related to two of the school climate scales, affirming diversity and reporting and seeking help, were unexpected. Positive student perceptions of these aspects of the school climate were associated with small increases in bully victimisation, whereas past research suggests that more positive student perceptions in the areas of affirming diversity (Hatzenbuehler and Keyes 2013; Norwich and Kelly 2004) and the mechanisms for reporting and seeking help (Bandyopadhyay et al. 2009; Gregory et al. 2010) should be associated with decreased levels of bullying. One possible explanation for our findings in these areas may involve superficial efforts by schools to improve either students' attitude to diversity or their awareness of mechanisms for reporting and seeking help. Although such efforts may indeed lead to students reporting positive scores for these aspects of the school climate, the lack of meaningful changes in school-wide normative beliefs about diversity (Aldridge et al. 2016) or bullying (Gendron et al. 2011) or students' expectations of staff members' reactions when issues are reported (Eliot et al. 2010) may make such efforts ineffective at reducing bullying behaviour. 


\section{Hypothesis 3-Relationships between School Climate and Life Satisfaction}

The school climate explained $54 \%$ of the variance in life satisfaction, suggesting that school climate has an important association with this aspect of youth wellbeing. Of the six school climate scales, three — school connectedness $(\beta=0.37, p<.001)$, affirming diversity $(\beta=0.08, p<.001)$, and reporting and seeking help $(\beta=0.05, p<.01)$ —were positively and statistically significantly related to life satisfaction. As was the case for bully victimisation, the effect for school connectedness was particularly strong. Overall, these findings support past research, which has indicated that students' life satisfaction is positively associated with their perceptions of school connectedness (Suldo et al. 2008; You et al. 2008) and schoolwide order and discipline (to which the mechanisms for reporting and seeking help contribute; Suldo et al., 2013). It was surprising, however that the two scales related to relationships (teacher support and peer connectedness) did not have statistically significant associations with life satisfaction in our study, despite past research indicating that interpersonal relationships are important for adolescents' life satisfaction (Suldo et al. 2008; Suldo et al. 2013).

\section{Hypothesis 4-Relationships between Life Satisfaction and Students' Resilience and Experiences of Bullying}

Of the two possible direct relationships between the outcome variables, only one (that between resilience and life satisfaction) was statistically significant $(\beta=0.36, p<.001)$. As such, students who reported more resilience were more likely to report satisfaction with life. Although bully victimisation was (as expected) negatively associated with life satisfaction $(\beta=-0.02)$, this relationship was small in magnitude and not statistically significant.

Our finding that bully victimisation was not statistically significantly related to life satisfaction was unexpected. Although the interrelationship between bullying victimisation and resilience was not examined in this study, it is possible that resilience acted as a buffer between the effects of bullying and life satisfaction. Alternatively, other factors such as aspects of the 
students' home and family environments may have been more important than experiences of bullying in determining adolescents' life satisfaction (Antaramian et al. 2008; Hills et al. 2014).

We also examined whether the school climate scales affected life satisfaction indirectly (that is, through a mediating variable). The simultaneous direct and indirect effects of the school climate scales on life satisfaction, reported in Table 5, indicated that there were statistically significant indirect effects for school connectedness $(p<.001)$, affirming diversity $(p<.001)$, and reporting and seeking help $(p<.01)$, with school connectedness having a particularly strong relationship with life satisfaction. As such, our results indicate that the school climate is associated with students' life satisfaction both directly and indirectly through the mediating influence of resilience.

Table 5 about here

\section{Educational Implications}

Given the existing evidence that many schools' climates do not reflect optimal psychosocial characteristics (Cohen et al. 2009; Felner et al. 2001), our findings add further weight to the call for schools to give increased attention to improving their climates. This section highlights key implications of our study for school-based practitioners.

\section{Promoting School Connectedness}

Of the six aspects of school climate that were included in this study, school connectedness had the strongest effect on all three outcomes (resilience, bullying, and life satisfaction; see Table 5). Given this finding, it is of particular importance for schools to actively pursue ways to promote school connectedness.

Based on reviews of research and the opinions of experts, resources have been developed that provide practical guidance for schools in this regard. For example, the US 
Centers for Disease Control and Prevention (2009) have detailed practical steps to promote school connectedness through attending to school decision-making processes; opportunities for family involvement in schooling; students' social, emotional, and academic skills for success; classroom environments; teacher professional development; and relationships. Likewise, the Australian government's Mind Matters professional development programme provides practical guidance for strengthening school connectedness in terms of relationships, belonging, inclusion, and active participation (Mind Matters, n.d.). Finally, Allen et al. (2016) have provided a comprehensive socio-ecological framework and identified evidence-based practices that schools can use to promote school connectedness at individual, peer, teacher, and school-wide levels.

\section{Reducing Bullying Behaviour}

Our results showed that school connectedness, teacher support, and rule clarity were associated with reduced rates of bully victimisation. The previous section discussed improving school connectedness; this section, therefore, considers how schools might enhance teacher support and rule clarity.

To increase teacher support, schools could seek to raise teachers' awareness of the importance of this affective domain and consider how school operations afford opportunities for teachers to build relationships with students (particularly in high schools, where students move from teacher to teacher during the day; Orpinas and Horne 2009). Further, in the area of bullying specifically, schools could consider the need to challenge and change school-wide normative beliefs about what 'counts' as bullying and whether bullying is acceptable or 'normal' (Orpinas and Horne 2009; Yoon and Bauman 2014). Finally, given that past research has indicated that, when bullying occurs, many teachers are either unsure of how to respond or overestimate the efficacy of their responses (Crothers and Kolbert 2004), it is important for schools to facilitate teacher development in these areas.

In terms of improving rule clarity, schools could consider how they can: gain consensus on rules; effectively communicate the norms for behaviours across all members of the school 
community; consistently enforce rules; and reinforce desired behaviours (Gottfredson and Gottfredson 2001; Gregory and Cornell 2009; Olweus 1994). Importantly, schools should also consider whether they may be operating under an individual-deficit theory of problem behaviour causation, in which blame is placed entirely upon the individual student involved (Gottfredson and Gottfredson 2001); research suggests that, instead, schools should seek to operate within a theory that acknowledges environmental influences (including home and family influences, as well as the school climate) on student behaviour (Gottfredson et al. 2005). Finally, schools might consider restorative justice approaches, which emphasise offenders understanding the impact that their behaviour has on others (rather than imposing punishment on the offender; Hopkins 2002). With their focus on 'bad behaviour' rather than 'bad people', restorative justice approaches promote both the support and structure domains of school climate.

\section{Balancing Support and Structure for a Healthy School Climate}

Overall, our findings affirm past work that has emphasised that positive school climates require a balance of support and structure (Cornell and Huang 2016; Gregory and Cornell 2009; Gregory et al. 2010). For example, in our study, of the four aspects of school climate that were statistically significantly related to resilience, two (peer connectedness and school connectedness) involved adolescents' internal sense of belonging and being in relationships with others - support - whereas the other two (rule clarity and reporting and seeking help) related to mechanisms in the school that promote a safe and orderly environment-structure. Similarly, aspects of both support and structure were significantly associated with both improved life satisfaction and reduced bullying.

Although the calls to balance support and structure in healthy school climates are not new, there can be a tendency for schools to focus on aspects related to discipline and structure at the expense of promoting support-related psychosocial characteristics of the environment (Gottfredson and Gottfredson 2001; Gregory and Cornell 2009; Gregory et al. 2010). As such, our findings emphasise the need for educators and school leaders to more deliberately enhance 
the psychosocial nature of the school climate through attending to the levels of support available in terms of peer connectedness, teacher support, and school connectedness. Using questionnaires that capture students' perceptions of the current school climate (such as the WHITS questionnaire used in the present study; Aldridge \& Ala'i 2013) may be a productive starting point for schools in this effort.

\section{Limitations and Directions for Future Research}

As with any research, our study is not without limitations. First, our sample came from particular geographic locations; care should be taken when generalising our findings to locations outside the metropolitan areas of Adelaide and Perth.

Although the use of self-report data is well-supported as a valid and reliable means for examining learning environments (Fraser 2012) and affective student outcomes (Seligman et al. 2009; Suldo et al. 2009), the non-response rate for this study (23.8\%) raises the possibility that the results reported in this article may not reflect the experiences of all students. We note, however, that the response rate achieved in this study exceeds those reported elsewhere as being typical in both educational (Nulty 2008) and other (Morton et al 2012; Pace et al. 2012) fields.

The use of bootstrapping to address non-normal data relies on the assumption that the sample is representative of the associated population (Kline 2011). Our large sample size, the relatively high response rate, and the demographic similarity of our sample to the wider Australian population (see Table 1) support the validity of our use of bootstrapping; however, we acknowledge that it is possible that our sample differs from the population of Australian high school students in other unobserved ways.

In terms of the constructs and relationships examined, we note that constructs such as school climate, resilience, and life satisfaction can be defined in a range of ways (see, for example, Cohen et al. 2009; Kaplan 2013; Reyes et al. 2013; Rutter 2006; Wang and Degol 2016). To mitigate potential misinterpretation of our findings, we have taken care to clarify how 
we defined and measured each construct; future users of this research should attend to these clarifications carefully.

Our study was informed by an a priori conceptual framework, which was developed based on past research and theorising, and the SEM analysis tested the relationships in the directions indicated within this framework. It is important to acknowledge that the directions could, in fact, be different and that SEM can only demonstrate that a certain model fits databut not that the model is, in fact, the true model of the phenomena being examined (Kline 2011). Past research related to the constructs examined in our study has suggested that some relationships may even be recursive or bidirectional (Kasen et al. 2004; Martin et al. 2008; Suldo et al. 2009). Future longitudinal studies and evaluations of school interventions could shed further light on the directionality of these relationships.

The two unexpected findings in our study also warrant further research. First, it was surprising that both affirming diversity and the mechanisms for reporting and seeking help were associated with increased bullying. Future research should investigate how schools can improve these aspects of their school climate without generating unintended negative consequences such as an increase in bullying. Second, it was unexpected that experiences of bullying were not significantly associated with life satisfaction. This may have been due to students' resilience buffering the effect of bully victimisation on life satisfaction; this possibility should be examined in further studies that might involve a mixed methods approach (see for example, McChesney and Aldridge, 2019).

\section{Conclusion}

The study reported in this article extended past research by examining not only the relationships between the school climate and resilience, bully victimisation, and life satisfaction, but also whether resilience or bully victimisation mediated the relationship between the school climate and life satisfaction. Further, our study provided a detailed examination of the ways in which six distinct sub-constructs of school climate related to each of resilience, bully 
victimisation, and life satisfaction, particularly highlighting the importance of school connectedness. Given that 'school climate is malleable and can serve as a target for intervention' (Wang and Degol 2016, p. 317), understanding how specific aspects of school climate are linked to student outcomes has the potential to inform focused and strategic efforts by school-based practitioners.

Overall, the associations that were observed in our study support the importance of an ecological perspective on adolescent development — that is, a perspective that acknowledges that social and environmental factors have powerful influences on adolescents and their behaviour. As such, it is critical for educators to be attentive to the psychosocial climate within schools, recognising areas where this climate could be improved and then, through targeted improvement efforts, harnessing the influence of these environmental factors to achieve gains in other areas. Specifically, our study indicates that through deliberate efforts to improve key aspects of the school climate, schools may be able to decrease the prevalence of bullying and enhance students' resilience and life satisfaction. 


\section{References}

Aldridge, J. M., \& Ala'i, K. (2013). Assessing students' views of school climate: Developing and validating the What's Happening In This School? (WHITS) questionnaire. Improving Schools, 16(1), 47-66.

Aldridge, J. M., Fraser, B. J., Fozdar, F., Ala'i, K., Earnest, J., \& Afari, E. (2016). Students' perceptions of school climate as determinants of wellbeing, resilience and identity. Improving Schools, 19(1), 5-26.

Aldridge, J.M. \& McChesney, K. (2018). The relationships between school climate and adolescent mental health and wellbeing: A systematic literature review. International Journal of Educational Research, 88, 121-145. (Accepted Jan 28, 2018). DOI: 10.1016/j.jjer.2018.01.012

Aldridge, J. M., McChesney, K. R., \& Afari, E. (2017). The relationships between school climate, bullying and delinquent behaviours. Learning Environments Research. Advance online publication. doi: 10.1007/s10984-017-9249-6

Australian Consortium for Social and Political Research Inc. [ACSPRI] (n.d.). The Australian Survey of Social Attitudes. Retrieved from https://www.acspri.org.au/aussa

Allen, K., Vella-Brodrick, D., \& Waters, L. (2016). Fostering school belonging in secondary schools using a socio-ecological framework. Educational and Developmental Psychologist, 33(1), 97-121.

Antaramian, S. P., Huebner, E. S., \& Valois, R. F. (2008). Adolescent life satisfaction. Applied Psychology: An international review, 57(1), 112-126.

Australian Psychological Society. (2016). APS compass for life wellbeing survey. Retrieved from https://psychweek.org.au/wp/wp-content/uploads/2016/11/16APS-PW-SurveyWeb.pdf.

Bandyopadhyay, S., Cornell, D., \& Konold, T. (2009). Internal and external validity of three school climate scales from the School Climate Bullying Survey. School Psychology Review, 38, 338-355. 
Benard, B. (1997). Turning it around for all youth: From risk to resilience. ERIC/CUE Digest, 126.

Benard, B. (2004). Resiliency: What have we learned? San Francisco, CA: WestEd.

Benard, B., \& Slade, S. (2009). Listening to students: Moving from resilience research to youth development practice and school connectedness. In R. Gilman, E. S. Huebner, \& M. J. Furlong (Eds.), Handbook of positive psychology in schools (pp. 353-369). New York, NY: Routledge.

Berkowitz, R., Moore, H., Astor, R. A., \& Benbenishty, R. (2017). A research synthesis of the associations between socioeconomic background, inequality, school climate, and academic achievement. Review of Educational Research, 87(2), 425-469.

Bollen, K. A., \& Stine, R. A. (1993). Bootstrapping goodness-of-fit measures in structural equation modeling. In K. A. Bollen \& J. S. Long (Eds.), Testing structural equation models (pp. 111-135). Newbury Park, CA: Sage.

Center for School Health and Education. (2011). School climate, student success and the role of school-based health care. Retrieved from http://www.schoolbasedhealthcare.org/ /media/files/pdf/sbhc/school_climate.ashx

Centers for Disease Control and Prevention. (2009). School connectedness: Strategies for increasing protective factors among youth. Atlanta, GA: U.S. Department of Health and Human Services.

Cohen, J. (2013). Creating a positive school climate: A foundation for resilience. In S. Goldstein \& R. B. Brooks (Eds.), Handbook of resilience in children (pp. 411-423). New York, NY: Springer.

Cohen, J., McCabe, E. M., Michelli, N. M., \& Pickeral, T. (2009). School climate: Research, policy, practice, and teacher education. Teachers College Record, 111(1), 180-213.

Cornell, D., \& Huang, F. (2016). Authoritative school climate and high school student risk behavior: A cross-sectional multi-level analysis of student self-reports. Journal of Youth and Adolescence, 45(11), 2246-2259. 
Crothers, L. M., \& Kolbert, J. B. (2004). Comparing middle school teachers' and students' views on bullying and anti-bullying interventions. Journal of School Violence, 3(1), 1732.

Curran, P. J., West, S. G., \& Finch, J. F. (1996). The robustness of test statistics to nonnormality and specification error in confirmatory factor analysis. Psychological Methods, 1, 1629.

Currie, C., Zanotti, C., Morgan, A., Currie, D., de Looze, M., Roberts, C., . . Barnekow, V. (Eds.). (2012). Social determinants of health and well-being among young people:

Health Behaviour in School-Aged Children (HBSC) study: International report from the 2009/2010 survey. Copenhagen, Denmark: World Health Organisation Regional Office for Europe.

Demaray, M. K., \& Malecki, C. K. (2003). Perceptions of the frequency and importance of social support by students classified as victims, bullies, and bully/victims in an urban middle school. School Psychology Review, 32(3), 471-489.

Diener, E., Inglehart, R., \& Tay, L. (2013). Theory and validity of life satisfaction scales. Social Indicators Research, 112(3), 497-527.

Eliot, M., Cornell, D., Gregory, A., \& Fan, X. (2010). Supportive school climate and student willingness to seek help for bullying and threats of violence. Journal of School Psychology, 48(6), 533-553.

Falk, R. F., \& Miller, N. B. (1992). A primer for soft modeling. Akron, OH: University of Akron Press.

Felner, R. D., Favazza, A., Shim, M., Brand, S., Gu, K., \& Noonan, N. (2001). Whole school improvement and restructuring as prevention and promotion: Lessons from STEP and the project on high performance learning communities. Journal of School Psychology, 39(2), 177-202. 
Fergusson, D. M., \& Horwood, L. J. (2003). Resilience to childhood adversity: Results of a 21 year study. In S. S. Luthar (Ed.), Resilience and vulnerability: Adaptation to the context of childhood adversities (pp. 130-155). Cambridge, UK: Cambridge University Press.

Fornell, C., \& Larker, D. F. (1981). Evaluating structural equation models with unobservable variables and measurement error. Journal of Marketing Research, 18(1), 39-50.

Fraser, B. J. (2012). Classroom learning environments: Retrospect, context and prospect. In B. J. Fraser, K. Tobin, \& C. McRobbie (Eds.), Second international handbook of science education (pp. 1191-1239). Dordrecht, The Netherlands: Springer.

Friedli, L. (2009). Mental health, resilience and inequalities. Copenhagen, Denmark: World Health Organization.

Gendron, B. P., Williams, K. R., \& Guerra, N. G. (2011). An analysis of bullying among students within schools: Estimating the effects of individual normative beliefs, selfesteem, and school climate. Journal of School Violence, 10(2), 150-164.

Goldstein, S., \& Brooks, R. B. (2005). Why study resilience? In S. Goldstein \& R. B. Brooks (Eds.), Handbook of resilience in children. New York, NY: Kluwer.

Gottfredson, G. D., \& Gottfredson, D. C. (2001). What schools do to prevent delinquency and promote safe environments. Journal of Educational and Psychological Consultation, 12(4), 313-344.

Gottfredson, G. D., Gottfredson, D. C., Payne, A. A., \& Gottfredson, N. C. (2005). School climate predictors of school disorder: Results from a national study of delinquency prevention in schools. Journal of Research in Crime and Delinquency, 42(4), 412-444.

Gregory, A., \& Cornell, D. (2009). “Tolerating” adolescent needs: Moving beyond zero tolerance policies in high school. Theory into Practice, 48(2), 106-113.

Gregory, A., Cornell, D., Fan, X., Sheras, P., Shih, T., \& Huang, F. (2010). Authoritative school discipline: High school practices associated with lower bullying and victimization. Journal of Educational Psychology, 102(2), 483-496. 
Hair, J. F., Black, W. C., Babin, B. J., \& Anderson, R. E. (2010). Multivariate data analysis (7th ed.). Upper Saddle River, NJ: Prentice Hall.

Hatzenbuehler, M. L., \& Keyes, K. M. (2013). Inclusive anti-bullying policies and reduced risk of suicide attempts in lesbian and gay youth. Journal of Adolescent Health, 53(1), 2126.

Hills, K., Lyons, M., \& Huebner, E. S. (2014). Adolescents' life satisfaction. In A. C. Michalos (Ed.), Encyclopedia of quality of life and well-being research (pp. 71-75). Dordrecht, The Netherlands: Springer.

Hoffman, C. Y., Phillips, M. D., Daigle, L. E., \& Turner, M. G. (2016). Adult consequences of bully victimization: Are children or adolescents more vulnerable to the victimization experience? Youth Violence and Juvenile Justice, 15(4), 441-464.

Hong, J. S., \& Espelage, D. L. (2012). A review of research on bullying and peer victimization in school: An ecological system analysis. Aggression and Violent Behavior, 17(4), 311322.

Hopkins, B. (2002). Restorative justice in schools. Support for Learning, 17(3), 144-149.

Hopson, L. M., \& Lee, E. (2011). Mitigating the effect of family poverty on academic and behavioral outcomes: The role of school climate in middle and high school. Children and Youth Services Review, 33(11), 2221-2229.

Huebner, E. S., \& Gilman, R. (2014). Adolescent life satisfaction measurement. In A. C. Michalos (Ed.), Encyclopedia of quality of life and well-being research (pp. 37-40). Dordrecht, The Netherlands: Springer.

Huebner, E. S., Gilman, R., \& Ma, C. (2012). Perceived quality of life of children and youth. In K. C. Land, A. C. Michalos, \& M. J. Sirgy (Eds.), Handbook of social indicators and quality of life research (pp. 355-372). Dordrecht, The Netherlands: Springer.

Huebner, E. S., Suldo, S. M., Smith, L. C., \& McKnight, C. G. (2004). Life satisfaction in children and youth: Empirical foundations and implications for school psychologists. Psychology in the Schools, 41(1), 81-93. 
Kaplan, H. B. (2013). Reconceptualizing resilience. In S. Goldstein \& R. B. Brooks (Eds.), Handbook of resilience in children (pp. 39-55). Boston, MA: Springer.

Kasen, S., Berenson, K., Cohen, P., \& Johnson, J. G. (2004). The effects of school climate on changes in aggressive and other behaviors related to bullying. In S. M. Swearer \& D. L. Espelage (Eds.), Bullying in American schools: A social-ecological perspective on prevention and intervention (pp. 187-210). Mahwah, NJ: Erlbaum.

Kline, R. B. (2011). Principles and practices of structural equation modeling (3rd ed.). New York, NY: Guilford Press.

Li, Y., Lynch, A. D., Kalvin, C., Liu, J., \& Lerner, R. M. (2011). Peer relationships as a context for the development of school engagement during early adolescence. International Journal of Behavioral Development, 35(4), 329-342.

Martin, K., Huebner, E. S., \& Valois, R. F. (2008). Does life satisfaction predict victimization experiences in adolescence? Psychology in the Schools, 45(8), 705-714.

Masten, A. S. (2001). Ordinary magic: Resilience processes in development. American Psychologist, 56(3), 227-238.

Masten, A. S., Herbers, J. E., Cutuli, J. J., \& Lafavor, T. L. (2008). Promoting competence and resilience in the school context. Professional School Counselling, 12(2), 76-84.

McChesney, K.M., \& Aldridge, J.M. (2019). Weaving an interpretivist stance throughout mixed methods research. International Journal of Research and Method in Education, 42, $225-238$

McKnight, C. G., Huebner, E. S., \& Suldo, S. M. (2002). Relationships among stressful life events, temperament, problem behavior, and global life satisfaction in adolescents. Psychology in the Schools, 39(6), 677-687.

Mind Matters. (n.d.). Module 1.4: Relationships and belonging. Retrieved from https://www.mindmatters.edu.au/docs/default-source/learning-moduledocuments/mm_module1_4-moduleoverview.pdf?sfvrsn=2 
Mitchell, K. J., Ybarra, M., \& Finkelhor, D. (2007). The relative importance of online victimization in understanding depression, delinquency, and substance use. Child Maltreatment, 12(4), 314-324.

Modecki, K. L., Minchin, J., Harbaugh, A. G., Guerra, N. G., \& Runions, K. C. (2014). Bullying prevalence across contexts: A meta-analysis measuring cyber and traditional bullying. Journal of Adolescent Health, 55(5), 602-611.

Mok, M. M. C. (2018). Editorial. Educational Psychology, 38(1), 1-2.

Morton, S. M. B. (2012). In the 21st century, what is an acceptable response rate? Australian and New Zealand Journal of Public Health, 36(2), 106-108.

National Center for Injury Prevention and Control. (2014). The relationship between bullying and suicide: What we know and what it means for schools. Chamblee, GA: Author.

Norwich, B., \& Kelly, N. (2004). Pupils' views on inclusion: Moderate learning difficulties and bullying in mainstream and special schools. British Educational Research Journal, $30(1), 43-65$.

Nulty, D. D. (2008). The adequacy of response rates to online and paper surveys: What can be done? Assessment and Evaluation in Higher Education, 33(3), 301-314.

Nunnally, J. C., \& Bernstein, I. H. (1994). Psychometric theory. New York, NY: McGraw-Hill.

O’Dougherty Wright, M., Masten, A. S., \& Narayan, A. J. (2013). Resilience processes in development: Four waves of research on positive adaptation in the context of adversity. In S. Goldstein \& R. B. Brooks (Eds.), Handbook of resilience in children (pp. 15-37). Boston, MA: Springer.

Organisation for Economic Co-operation and Development [OECD]. (n.d.). Better Life Initiative: Measuring Well-Being and Progress. Retrieved from http://www.oecd.org/statistics/better-life-initiative.htm

Olweus, D. (1994). Annotation: Bullying at school: Basic facts and effects of a school based intervention program. Journal of Child Psychology and Psychiatry, 35(7), 1171-1190. 
Orpinas, P., \& Horne, A. M. (2009). Creating a positive school climate and developing social competence. In S. Jimerson, S. M. Swearer, \& D. L. Espelage (Eds.), Handbook of bullying in schools: An international perspective (pp. 49-59). New York, NY:

Routledge.

Pace, R., Pluye, P., Bartlett, G., Macaulay, A. C., Salsberg, J., Jagosh, J., \& Seller, R. (2012). Testing the reliability and efficiency of the pilot Mixed Methods Appraisal Tool (MMAT) for systematic mixed studies review. International Journal of Nursing Studies, 49(1), 47-53.

Proctor, C. L., Linley, P. A., \& Maltby, J. (2009). Youth life satisfaction: A review of the literature. Journal of Happiness Studies, 10(5), 583-630.

Raykov, T., \& Marcoulides, G. A. (2008). An introduction to applied multivariate statistics. New York, NY: Guilford Press.

Reyes, J. A., Elias, M. J., Parker, S. J., \& Rosenblatt, J. L. (2013). Promoting educational equity in disadvantaged youth: The role of resilience and social-emotional learning. In S. Goldstein \& R. B. Brooks (Eds.), Handbook of resilience in children (pp. 349-370). Boston, MA: Springer.

Riekie, H., Aldridge, J. M., \& Afari, E. (2017). The role of the school climate in high school students' mental health and identity formation: A South Australian study. British Educational Research Journal, 43(1), 95-123.

Rutter, M. (2006). Implications of resilience concepts for scientific understanding. Annals of the New York Academy of Sciences, 1094(1), 1-12.

Schoon, I., \& Bynner, J. (2003). Risk and resilience in the life course: Implications for interventions and social policies. Journal of Youth Studies, 6(1), 21-31.

Seligman, M. E. P., Ernst, R. M., Gillham, J., Reivich, K., \& Linkins, M. (2009). Positive education: Positive psychology and classroom interventions. Oxford Review of Education, 35(3), 293-311. 
Suldo, S. M., \& Huebner, E. S. (2004). Does life satisfaction moderate the effects of stressful life events on psychopathological behavior during adolescence? School Psychology Quarterly, 19(2), 93-105.

Suldo, S. M., Huebner, E. S., Friedrich, A. A., \& Gilman, R. (2009). Life satisfaction. In R. Gilman, E. S. Huebner, \& M. J. Furlong (Eds.), Handbook of positive psychology in schools (pp. 27-35). New York, NY: Routledge.

Suldo, S. M., Shaffer, E. J., \& Riley, K. N. (2008). A social-cognitive-behavioral model of academic predictors of adolescents' life satisfaction. School Psychology Quarterly, 23(1), 56-69.

Suldo, S. M., Thalji-Raitano, A., Hasemeyer, M., Gelley, C. D., \& Hoy, B. (2013).

Understanding middle school students life satisfaction: Does school climate matter? Applied Research in Quality of Life, 8(2), 169-182.

Turner, I., Reynolds, K. J., Lee, E., Subasic, E., \& Bromhead, D. (2014). Well-being, school climate, and the social identity process: A latent growth model study of bullying perpetration and peer victimization. School Psychology Quarterly, 29(3), 320-335.

Turner, M. G. (2013). Repeat bully victimizations and legal outcomes in a national sample: The impact over the life course. Retrieved from http://www.apa.org/news/press/releases/2013/08/bully-victimizations.pdf

UK Office for National Statistics. (2016). Measuring national well-being: Life satisfaction. Retrieved from: https://www.ons.gov.uk/peoplepopulationandcommunity/wellbeing/datasets/measuring nationalwellbeinglifesatisfaction

UK Office for National Statistics. (n.d.). Well-being. Retrieved from https://www.ons.gov.uk/peoplepopulationandcommunity/wellbeing United Nations. (n.d.). World Happiness Report. Retrieved from http://worldhappiness.report/ Wagnild, G. M., \& Young, H. M. (1993). Development and psychometric evaluation of the Resilience Scale. Journal of Nursing Measurement, 1(2), 165-178. 
Wang, C., Berry, B., \& Swearer, S. M. (2013). The critical role of school climate in effective bullying prevention. Theory into Practice, 52(4), 296-302.

Wang, M., \& Degol, J. L. (2016). School climate: A review of the construct, measurement, and impact on student outcomes. Educational Psychology Review, 28(2), 315-352.

Yoon, J., \& Bauman, S. (2014). Teachers: A critical but overlooked component of bullying prevention and intervention. Theory into Practice, 53(4), 308-314.

You, S., Furlong, M. J., Felix, E., Sharkey, J. D., \& Tanigawa, D. (2008). Relations among school connectedness, hope, life satisfaction, and bully victimization. Psychology in the Schools, 45(5), 446-460. 


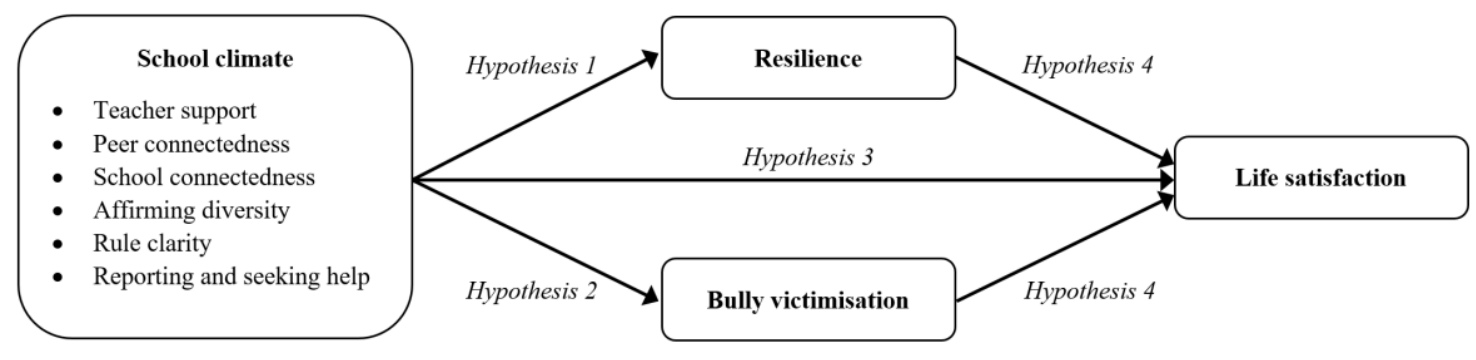

Figure 1 Conceptual framework used in the study 


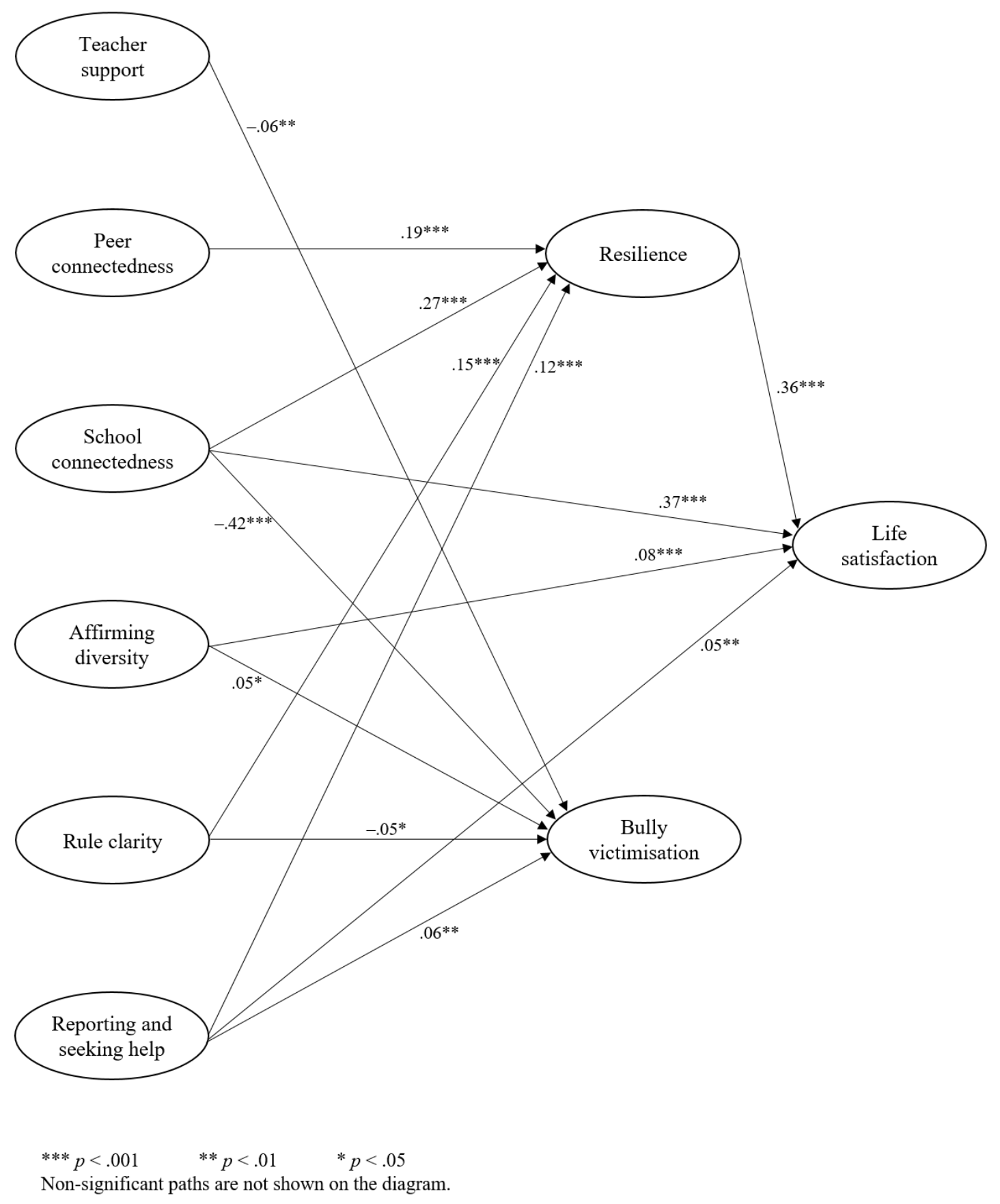

Figure 2 Structural equation modelling results showing statistically significant relationships between six school climate constructs and bully victimisation, resilience, and life satisfaction 
Table 1 Demographic breakdown of the study sample compared to the Australian population

\begin{tabular}{lcc}
\hline Demographic variable & Study sample & Australian population \\
\hline Gender & & \\
Male & $41.2 \%$ & $49.7 \%$ \\
Female & $53.8 \%$ & - \\
No response & $5.0 \%$ & \\
\hline Birthplace & & $71.5 \%$ \\
Australia & $79.6 \%$ & $28.5 \%$ \\
Overseas & $20.4 \%$ & \\
\hline First language / Language spoken at home $*$ & & $76.7 \%$ \\
English & $83.2 \%$ & $18.3 \%$ \\
Other & $16.8 \%$ & $5.0 \%$ \\
No response & - & \\
\hline
\end{tabular}

Study sample $N=6,120$.

Source for Australian population statistics: www.abs.govt.au

* Our survey asked students to identify their first language, whereas the Australian census collects data on the primary language spoken at home. For most people, however, the primary language spoken at home is likely to be their first language; as such, this data is still useful for providing a general indication of the representativeness of the study sample compared to the Australian population. 


\begin{tabular}{|c|c|c|c|}
\hline Statistic & Feature examined & Criterion & Source of criterion \\
\hline \multicolumn{4}{|l|}{ Determining the suitability of the data for SEM analysis: } \\
\hline Skewness & Symmetry & Absolute value less than 3.0 & Kline (2011) \\
\hline Kurtosis & Extreme values & Absolute value less than 10.0 & Kline (2011) \\
\hline Mardia's coefficient & Multivariate normality & Less than $p(p+2)$ & Raykov and Marcoulides (2008) \\
\hline \multicolumn{4}{|c|}{ Examining the reliability and validity of the measurement model: } \\
\hline Standardised factor loadings & Item reliability & Greater than .70 & $\begin{array}{l}\text { Hair, Black, Babin, and Anderson } \\
\text { (2010) }\end{array}$ \\
\hline Composite reliability (CR) & Construct reliability & Minimum value of .70 & Nunnally and Bernstein (1994) \\
\hline Average variance extracted (AVE) & Convergent validity & Minimum value of .50 & Fornell and Larker (1981) \\
\hline Square root of AVE & Discriminant validity & $\begin{array}{l}\text { Greater than the correlations between the construct } \\
\text { being examined and all of the other constructs }\end{array}$ & Fornell and Larker (1981) \\
\hline \multicolumn{4}{|l|}{ Evaluating the model fit: } \\
\hline Chi-squared / degrees of freedom $\left(\chi^{2} / \mathrm{df}\right)$ & Absolute fit & Less than 3 & Kline (2011) \\
\hline Goodness of fit index (GFI) & Absolute fit & Equal to or greater than .90 & Kline (2011) \\
\hline Adjusted goodness of fit index (AGFI) & Absolute fit & Equal to or greater than .90 & Kline (2011) \\
\hline Standardised root mean squared residual (SRMR) & Absolute fit & Less than .08 & Kline (2011) \\
\hline Tucker Lewis index (TLI) & Relative fit & Equal to or greater than .90 & Kline (2011) \\
\hline Incremental fit index (IFI) & Relative fit & Equal to or greater than .90 & Kline (2011) \\
\hline Comparative fit index (CFI) & Non-centrality based fit & Equal to or greater than .90 & Kline (2011) \\
\hline Root mean square error of approximation (RMSEA) & Non-centrality based fit & Less than .05 & Kline (2011) \\
\hline \multicolumn{4}{|l|}{ Evaluating the explanatory power of the model: } \\
\hline Coefficient of determination $\left(R^{2}\right)$ & Explanatory power & Greater than .10 & Falk and Miller (1992) \\
\hline
\end{tabular}




\begin{tabular}{|c|c|c|c|c|c|c|c|c|c|c|c|}
\hline Construct & $\begin{array}{l}\text { Composite } \\
\text { reliability }\end{array}$ & $\begin{array}{l}\text { Average } \\
\text { variance } \\
\text { extracted }\end{array}$ & TS & $\mathrm{PC}$ & $\mathrm{SC}$ & $\mathrm{AD}$ & $\mathrm{RC}$ & RSH & B & $\mathrm{R}$ & LS \\
\hline Teacher support (TS) & .91 & .64 & (.80) & & & & & & & & \\
\hline Peer connectedness (PC) & .87 & .54 & $.38 * *$ & (.73) & & & & & & & \\
\hline School connectedness (SC) & .93 & .68 & $.62 * *$ & $.62 * *$ & $(.82)$ & & & & & & \\
\hline Affirming diversity (AD) & .86 & .50 & $.54 * *$ & $.39 * *$ & $.52 * *$ & (.71) & & & & & \\
\hline Rule clarity (RC) & .90 & .60 & $.57 * *$ & $.36^{* *}$ & $.59 * *$ & $.50 * *$ & $(.77)$ & & & & \\
\hline Reporting \& seeking help (RSH) & .88 & .56 & $.56^{* *}$ & $.39 * *$ & $.53 * *$ & $.52 * *$ & $.63 * *$ & (.75) & & & \\
\hline Bully victimisation (BV) & .91 & .64 & $-.22 * *$ & $-.24 * *$ & $-.33 * *$ & $-.15 * *$ & $-.18 * *$ & $-.15 * *$ & $(.80)$ & & \\
\hline Resilience (R) & .92 & .65 & $.43^{* *}$ & $.46^{* *}$ & $.57 * *$ & $.39 * *$ & $.47 * *$ & $.45^{* *}$ & $-.17 * *$ & $(.81)$ & \\
\hline Life satisfaction (LS) & .91 & .64 & $.40^{* *}$ & $.42 * *$ & $.57 * *$ & $.38 * *$ & $.41 * *$ & $.39 * *$ & $-.29 * *$ & $.53^{* *}$ & (.80) \\
\hline
\end{tabular}

Composite reliability: $\frac{\left(\sum \lambda\right)^{2}}{\left(\sum \lambda\right)^{2}+\sum\left(1-\lambda^{2}\right)}$

Average variance extracted: $\frac{\sum \lambda^{2}}{\sum \lambda^{2}+\sum\left(1-\lambda^{2}\right)}$

The bold elements in the main diagonal are the square roots of the average variance extracted. 
Table 4 Coefficients of determination (R2) for the outcome variables

\begin{tabular}{cc}
\hline Outcome variable & Coefficient of determination $\left(R^{2}\right)$ \\
\hline Resilience & .41 \\
Bully victimisation & .16 \\
Life satisfaction & .54 \\
\hline
\end{tabular}


Table 5 Standardised direct, indirect, and total effects of school climate on life satisfaction

\begin{tabular}{cccc}
\hline School climate scale & \multicolumn{2}{c}{ Effects on life satisfaction } \\
\cline { 2 - 4 } Teacher support & Direct & Indirect & Total \\
Peer connectedness & .01 & .01 & .02 \\
School connectedness & .02 & .07 & .09 \\
Affirming diversity & $.37^{* * *}$ & $.10^{* * *}$ & $.07^{* * * *}$ \\
Rule clarity & $.08^{* * *}$ & $.01^{* * *}$ & -.03 \\
Reporting and seeking help & -.02 & .05 & $.04^{* * *}$ \\
\hline$* * p<.001 ; * * p<.01$ & $.05^{* *}$ & &
\end{tabular}

